\title{
Securing a Fair Trial Through Exclusionary Rules: Do Theory and Practice Form a Well-Balanced Whole?
}

\author{
Susanne Knickmeier
}

\begin{abstract}
This chapter describes practitioners' understanding of excluding illegally obtained evidence. To gain deeper insight into the applicability of the exclusion of evidence obtained through illegal means and to evaluate regulations that have been implemented, fourteen experts from different legal professions (lawyers, judges, prosecutors) and countries (Germany, Singapore, Switzerland and Taiwan (ROC)) were interviewed about their experiences. All legal systems are faced with the use of illegally obtained evidence. Based on qualitatively analyzed data the frequency of the applicability of exclusionary rules, the types of cases in which they are seen, and experts' attitudes towards the function of exclusionary rules are described. Violations of rules around the gathering of evidence is a highly sensitive topic, particularly as the state (represented by police officers and prosecutors) plays a central and powerful role. To find out if exclusionary rules do indeed result in a more impartial trial or if further protective measures are required, factors influencing the procurement of evidence and the decision-making process around the legality of such procurement were evaluated. Subsequently, difficulties that law enforcement agencies and criminal courts are faced with were outlined, with an emphasis on the application of the law and the limitations in safeguarding criminal investigations and proceedings. Concluding remarks highlight best practices in securing a fair trial as well as ancillary measures (including unwritten techniques) that may be utilized to optimize the utility of exclusionary rules.
\end{abstract}

\footnotetext{
S. Knickmeier $(\square)$

Department of Criminology, Max Planck Institute for Foreign and International Criminal Law, Freiburg, Germany

e-mail: s.knickmeier@mpicc.de

(C) The Author(s) 2019

S. Gless and T. Richter (eds.), Do Exclusionary Rules Ensure a Fair Trial?

Ius Gentium: Comparative Perspectives on Law and Justice 74,

https://doi.org/10.1007/978-3-030-12520-2_11
} 


\section{Theory and Practice}

The project "Securing a fair trial through excluding evidence? A comparative perspective" fulfills the need to determine features of the criminal process that are conducive to enhancing respect for human rights in different legal and cultural environments. The legal situation is described in the country reports in the previous chapters. But how do exclusionary rules function in legal practice? Does practitioners' understanding of excluding illegally obtained evidences comply with the law? What are experts' experiences concerning the applicability and frequency of exclusionary rules in criminal proceedings? Are techniques of taking evidence that are forbidden really not used? How can violations be proved? Where do the experts identify gaps of protection, limitations of exclusionary rules and possible safeguards? Which potential alternatives and supplementary means of nudging law enforcement are identified? What ancillary measures (also not written ones) may be utilized to make exclusionary rules effective? To gain a deeper insight into the applicability of the exclusion of evidence obtained by illegal means and to evaluate implemented legal regulations, experts from different legal professions and countries were interviewed about their field experience.

\section{Data Collection and Analysis}

The aim of the interviews was mainly explorative and partly theoretical-based. Explorative interviews seek to get information about the research field, the experts' knowledge about their business as well as about their contextual knowledge. ${ }^{1}$ Results from qualitative research based on a small number of interviews are not representative and do not allow for any generalization or statistical extrapolation. ${ }^{2}$ Nevertheless, the results provide an insight into the application of exclusionary rules, the evaluation of existing measures, potential gaps of protection and alternative measures to secure a fair trial.

\subsection{Collection of Data}

The expert interviews were conducted using a qualitative interview guideline. Semi-structured interviews are appropriate to get open answers, to describe a problem and to access the implementation of legal regulations. ${ }^{3}$ It is in the nature of things that for explorative aims, standardized questions could hardly be formulated.

\footnotetext{
${ }^{1}$ Bogner/Littig/Menz, 2014 at 23.

${ }^{2}$ Mayring, 2015 at 20.

${ }^{3}$ Mayring, 2015 at 23.
} 
Guideline-based interviews enable the interviewer to encourage the expert to report complex issues and to cover different perspectives of the research question. ${ }^{4}$ Therefore, the guideline included several questions to induce reporting, but also some hypothetical questions to explore the expert's attitude towards potential problems. The guideline also enabled the interviewer to follow a common thread of topics, which is important to analyze and compare the given information and perspectives. ${ }^{5}$ The guideline also included some standardized detailed questions to ensure that certain questions were asked. If not discussed in the interview, these questions were then discussed at the end of the interview.

In the following study, fourteen interviews from Germany (5), Switzerland (2), Taiwan (ROC) (4) and Singapore (3) were included. The interviews were conducted in the years from 2015 to 2017. Depending on specific circumstances, interviews lasted between 27 and $80 \mathrm{~min}$ with an average duration of $48 \mathrm{~min}$. The sample of experts covered all legal professions and included five judges, three prosecutors and three lawyers with long-term experience (at least five years) in the field of criminal law and criminal proceedings. (Police officers or police investigators were not questioned). Each professional group plays a special role within criminal proceedings and were able to describe the applicability of securing a fair trial from a different perspective. Several experts have worked in different legal professions, with professional experience as a prosecutor, judge or lawyer. The change of professional positions enabled the affected experts to obtain insights in different positions from different points of view, which made them valuable for explorative expert interviews. Experts were selected from European and Asian countries with different legal systems. Access to the sample of interviewees was possible due to personal contacts by the project team in Germany, Switzerland, Taiwan (ROC) and Singapore. The guideline-based interviews were conducted in German and English, the Taiwanese ones were partly discussed in Chinese and translated into English by a member of the project team familiar with the aims of the interviews. An extraordinary challenge occurred by conducting the interviews in different languages, particularly in interviews, in which neither the expert nor the interviewee were native speakers. To mitigate content-related problems due to language difficulties, the interviews were conducted by members of the project-team familiar with the legal situation in the expert's country and, if possible, with the expert's language. ${ }^{6}$ The interviews were audio-recorded and transcribed. To ensure anonymity, interviews are cited by using the country and a number.

\footnotetext{
${ }^{4}$ Gläser/Laudel, 2010 at 116.

${ }^{5}$ Gläser/Laudel, 2010 at 116 and 145.

${ }^{6}$ Bogner/Littig/Menz, 2014 at 44 et seq.
} 


\subsection{Data Analysis}

The collected data were analyzed by qualitative content analysis ${ }^{7}$ with the aim to evaluate the legal implementation, to identify the legal reality and to examine motivations and best practices to secure a fair trial. A content analysis is a technique to analyze a document produced within a communication process through structuring and systematically analyzing the text on the basis of categories and adding explanations. $^{8}$ There are several approaches to conduct a qualitative content analysis, which cannot be discussed in this framework. Despite limitations, the qualitative content analysis was chosen as the method to analyze the interview data. It enables researchers to structure the interviews referring to the research questions, to structure the extracted data referring to an empirical and theoretical basis, to interpret them, but also to keep an open mind concerning information that was not expected before the data collection. After the content was structured on the basis of categories, the extracted text passages were either theory-based encoded and analysed or codes were developed on the basis of the extracted text passages. Categories included, for example: function of exclusionary rules, kinds of exclusionary rules, knowledge of illegally obtained evidence, awareness of exclusionary rules, motivation to obtain evidence legally and consequences for officers after the illegal obtainment of evidence. The categories and codes were developed on the basis of the theoretical framework (see below) and refer to the hypothesis that exclusionary rules secure a fair trial; this hypothesis was examined by several assumptions compiled from empirical and theoretical approaches. The leading questions were:

(1) The function and role of exclusionary rules within criminal proceedings: If exclusionary rules secure a fair trial, it is essential to get information about the frequency of their applicability, the kind of cases they cover and the experts' attitudes towards the function of exclusionary rules (Sect. 3.2).

(2) Difficulties and limitations: This part examines legal difficulties in applying exclusionary rules as well as limitations to obtaining evidence legally. To evaluate if exclusionary rules secure a fair trial or whether further protective measures are required, it was necessary to know which factors and decisions influence the procurement of admissible evidence (Sect. 3.3).

(3) Compliance with rules to obtain evidence: As norm compliance and prevention require awareness, the awareness for exclusionary rules in criminal proceedings was considered in a first step to evaluate compliance with exclusionary rules and rules to obtain evidence. Secondly, possible motivations for norm compliance in the field of obtaining evidence were discussed to examine which measures were suitable and effective to secure a fair trial, and whether,

\footnotetext{
${ }^{7}$ The German term "Inhaltsanalyse" was translated as "content analysis". It includes a qualitative text analysis without quantitative elements.

${ }^{8}$ Gläser/Laudel, 2010 at 197; Mayring, 2002 at 114 et seq.
} 
for example, exclusionary rules could be strengthened through additional protective measures (Sect. 3.4).

\section{Do Theory and Practice Form a Well-Balanced Whole?}

In legal theory, exclusionary rules are implemented to secure a fair trial. But do theory and practice form a well-balanced whole? Do exclusionary rules secure a fair trial or is their applicability limited?

\subsection{Theoretical Considerations}

How can a fair trial be secured? In other words: which strategies can be applied to ensure evidence is obtained legally? In order to regulate criminal proceedings and to secure human rights within proceedings, governments establish laws and rules, for example exclusionary rules, which should be observed by police, prosecutors and judges. The rationale behind exclusionary rules is the expectation that law enforcement officers will refrain from employing prohibited evidence-gathering methods if they know that physical and testimonial evidence obtained by illegal methods will be excluded. It is assumed that they will realize that using such methods will not contribute to convicting the suspect and are therefore useless.

But how can compliance with the law be achieved? Which factors motivate people to comply with rules? Referring to social psychological theories, people can be intrinsically or extrinsically motivated to comply with existing rules. People's compliance with the law can be obtained through deterrence strategies (so-called instrumental strategies), which means that individuals are afraid of punishment (referring to the idea of general prevention), for example consequences under criminal or labor law. As an action theory, the rational-choice-theory is inter alia based on the assumption that people balance advantages and disadvantages before deciding how they react. Referring to the rational-choice-theory, potential offenders are deterred from violating rules, if the costs of criminal offences are higher than the advantages. ${ }^{9}$ Based on this idea, the situational crime prevention theory proposed measures that reduce the opportunity for crime and increase the risk of detection, for example through control measures or surveillance (e.g., audio- or video-recording of interrogations, interrogations conducted by at least two officers or physical examination of an arrested person). ${ }^{10}$ Yet, it is assumed that besides rational choice, normative considerations also play an equally important role in the

\footnotetext{
${ }^{9}$ Becker, 1968 at 207 et seq.

${ }^{10}$ Clarke, 1997 at 4 et seq.
} 
willingness of people to comply with the law. ${ }^{11}$ Enforcement of legal rules is linked to people's attitudes towards trust in justice, legitimacy, but also to the acceptance of a rule, which in the case of exclusionary rules is the legal taking of evidence respecting the suspect's rights. The acceptance of a rule is, therewith, one key precondition for norm compliance. ${ }^{12}$ In this context, Tyler pointed out: "If people view compliance with the law as appropriate because of their attitudes about how they should behave they will voluntarily assume the obligation to follow legal rules". ${ }^{13}$ Following this approach, the acceptance of rules depends on the individual's attitudes and conviction that a rule is morally legitimized. ${ }^{14}$ To achieve the acceptance of legal rules, people have to be convinced of their moral alignment with the rule, for example through training measures, educational work and communication between all actors concerned. While instrumental compliance includes external factors and people's self-interest not to be detected and punished, normative compliance focuses on the acceptance of a legal rule and its legitimacy, even if norm compliance is not to their own advantage. ${ }^{15}$ Referring to these theoretical ideas, the following section examines the hypothesis that exclusionary rules as an instrumental strategy secure a fair trial.

\subsection{Legal Rules in Practice}

The following chapter includes the function of exclusionary rules according to practitioners, the frequency of exclusionary rules in criminal proceedings, kinds of exclusionary rules in the daily work of practitioners as well as controversially discussed topics in practice. The results have to be considered in light of national legal rules and legal cultures. For example, the relationship between police and the prosecution service differs in the surveyed countries. In Germany, the prosecution service is responsible for preliminary proceedings and police officers are auxiliary officers of the prosecutor's office, while in Singapore the police and prosecution are different organizational entities. ${ }^{16}$

\subsubsection{Function of Exclusionary Rules}

One of the core questions concerns the function of exclusionary rules in criminal proceedings from the experts' perspective. The function of exclusionary rules is still

\footnotetext{
${ }^{11}$ See Tyler, 1990; Lind/Tyler, 1988.

${ }^{12}$ Tyler, 2003 at 284.

${ }^{13}$ Tyler, 1990 at 3.

${ }^{14}$ Tyler, 1990 at 4.

${ }^{15}$ Bottoms, 2001 at 90; Jackson et al., 2012 at 1053.

${ }^{16}$ Sing_02, 00:12:04.
} 
discussed between scholars and lawyers. ${ }^{17}$ Should they (a) discipline police or the prosecution service, (b) protect the legal system, human rights or the integrity of court proceedings, (c) maintain legal certainty or justice or (d) ensure that the trial court does not consider inherently unreliable evidence? Criminal proceedings contain a natural conflict between the retrieval of information and substantive truth. For this reason, criminal proceedings consist of difficult challenges to verify whether a piece of information was gained lawfully and if it is valid and reliable. ${ }^{18}$

Despite some differences between the legal systems in the surveyed countries, there are no controversial opinions in the analyzed interviews. According to the experts, exclusionary rules protect the rights of the accused person and ensure a fair trial. ${ }^{19}$ Even if it is not the primary objective and maybe not suitable, the exclusion of illegally obtained evidence could help to discipline police officers and to demonstrate to investigative officers that information obtained illegally is useless. ${ }^{20}$ One expert added to the latter argument that exclusionary rules have a disciplining effect, as police are usually interested in excellent work. ${ }^{21}$ Additionally, exclusionary rules uphold the rule of law, the principle of a fair trial, the integrity of the proceeding and the accused's rights. ${ }^{22}$ Nevertheless, conflicts can occur between the protection of the accused's rights and the protection of obtaining evidence to get valid information. ${ }^{23}$ In this context, a German expert pointed out that a judge or prosecutor never knows if the accused really committed the crime and needs to prove the accused's guilt in a fair trial using lawfully obtained evidence. ${ }^{24}$

\subsubsection{Frequency of Exclusionary Rules in Practice}

Next, the experts were asked about their experiences with illegally obtained evidence. All experts emphasized that cases concerning the exclusion of illegally obtained evidences are rare. The Taiwanese interviewees pointed out that their safeguards to obtain evidence legally have been improved in the last thirty years, particularly after the legal reform in $2003 .{ }^{25}$ Nowadays the system works and the number of cases in which evidences have to be excluded are only a few. ${ }^{26}$

\footnotetext{
${ }^{17} \mathrm{Jugl}, 2017$ at 53.

${ }^{18}$ Germ_03, 01:16:01, 01:17:16.

${ }^{19} \mathrm{Ch} \_01$, Sec. 4; Germ_02, 01:05:00; Germ_03, 01:16:01; Sing_02, 01:03:51; Taiw_02, 00:41:37.

${ }^{20} \mathrm{Ch} \_01$, Sec. 4; Germ_02, 01:06:13; Germ_03, 01:24:06; Sing_03, 00:33:51, 00:37:42; Taiw_02, 00:41:16; Taiw_03, 01:10:37.

${ }^{21}$ Germ_05, 00:12:01.

${ }^{22}$ Germ_02, 01:05:00; Germ_03, 01:16:01; Germ_05, 00:13:11; Sing_02, 01:03:51; Taiw_02, 00:41:37.

${ }^{23}$ Germ_03, 01:16:01.

${ }^{24}$ Germ_03, 01:37:20.

${ }^{25}$ Taiw_04, 00:03:42.

${ }^{26}$ Taiw_02, 00:14:18.
} 
According to the experts, the estimated number of cases dealing with exclusionary rules is usually far below $10 \%$ of their cases. Some practitioners pointed out that they are only discussed in exceptional cases, for example: in 5 out of 1500 cases or less than 10 cases in the last five years. ${ }^{27}$ Depending on the area of responsibility, the problem of exclusionary rules can be discussed more regularly. One judge dealing with serious cases in a Grand Criminal Chamber of a regional court guessed that exclusionary rules were discussed in three out of 15 cases (20\%). This number can be explained partly via the extent of cases concerning serious criminal offences like murder and manslaughter. Torture exists only in very exceptional cases and no expert has ever dealt with such a case or with other coercive measures in hearings. German experts pointed out that cases of torture or the threat of torture are hardly conceivable, ${ }^{28}$ except the well-known Gäfgen-case in $2003 .{ }^{29}$ In this context, one German expert emphasized that torture is absolutely prohibited. Any possible exception must not be discussed, even if the exception includes, like in the Gäfgen-case, saving the life of a person. Exemptions on the ban of torture would lead to a dangerous slippery slope and open the discussion of when and which kind of torture should be possible. ${ }^{30}$ All experts agreed that the number of illegally obtained confessions is significantly smaller than the number of cases concerning other pieces of unlawfully obtained evidence, for example unlawful surveillance of telecommunication. ${ }^{31}$

\subsubsection{Kind of Exclusionary Rules in Practice}

Errors leading to exclusionary rules occur particularly in connection with unlawful searches, defective warrants, instructions, telecommunication surveillances or undercover investigations. ${ }^{32}$ In cases involving searches in Taiwan (ROC), the use of a voluntary agreement from the accused can be questioned. Police do not always point out that the agreement is voluntary and the affected person is allowed to deny the signature. ${ }^{33}$ Sometimes police officers misjudge the legal preconditions of warrants or other measures of taking evidence. For example: a situation of imminent danger is assumed by police, while the prosecutor a posteriori denied it ${ }^{34} \mathrm{Next}$ to legal misjudgement, necessary decisions under time pressure, lack of time and

\footnotetext{
${ }^{27} \mathrm{Ch} \_01$, Sec. 8; Ch_02, 00:02:33; Germ_01, 00:01:14; Sing_02, 00:04:11; Taiw_04, 00:03:06.

${ }^{28}$ Germ_01, 00:08:41; Germ_02, 00:56:49; Germ_04, 00:04:42.

${ }^{29}$ See Weigend, National Report Germany.

${ }^{30}$ Germ_04, 00:51:15.

${ }^{31} \mathrm{Ch} \_01$, Sec. 6; Germ_04, 00:04:42; Germ_05, 00:18:56.

${ }^{32}$ Germ_01, 00:02:21, 00:44:57; Germ_03, 00:03:15; Germ_04, 00:04:42, 00:05:53; Germ_05, 00:05:24, 00:10:09; Taiw_02, 00:14:18, 00:23:33; Taiw_03, 00:29:48, 00:43:22.

${ }^{33}$ Taiw_03, 00:43:22 et seq.

${ }^{34}$ Germ_04, 00:04:42; Taiw_04, 00:11:25.
} 
overload of police or prosecutors are mentioned as potential reasons for illegally obtained evidence. ${ }^{35}$ In Switzerland, the right to participate in interrogations is a typical problem. ${ }^{36}$ Referring to Art. 147 Swiss Code of Criminal Procedure, ${ }^{37}$ the parties involved in the criminal proceedings have the right to attend measures of taking evidence by the prosecution service. In cases with several accused parties, every accused person has to be informed about hearings of his accomplices. Sometimes accomplices are interrogated independently without giving notice. ${ }^{38}$ In Germany, in turn, the instruction of offenders and particularly of their relatives are error-prone, as the legal situation in cases of instructing relatives can be very difficult. $^{39}$

The consequences of exclusionary rules for the criminal proceeding are difficult to evaluate. In as far as it is not the only or main evidence that is being excluded, the exclusion of illegally obtained evidence has no significant impact on the criminal proceedings, as there is usually corroborative evidence that can be gathered. Experts pointed out that the investigation process and judgement are usually based on several pieces of evidence. It is really unusual to rely on only one piece of evidence which might be unreliable, or on the accused's statement which the accused could deny in court. ${ }^{40}$

\subsection{Difficulties and Limitations to Secure a Fair Trial Through Exclusionary Rules}

The following chapter describes challenges that law enforcement agencies and criminal courts are faced with, particularly concerning difficulties in applying the law and limitations of safeguarding criminal investigations and proceedings.

\subsubsection{Difficulties in Applying the Law}

One difficulty concerns the incorrect application of the law to legally difficult questions. Where is the borderline between protecting core fundamental rights and the need to use procedures to get a rational suspect to confess $?^{41}$ Could a consistent interrogation of twelve hours or an uncomfortable interrogation room result in

\footnotetext{
${ }^{35}$ Germ_01, 00:04:31; Taiw_03, 00:26:53.

${ }^{36} \mathrm{Ch} \_02,00: 02: 33$.

${ }^{37}$ Schweizerische Strafprozessordnung vom 05.Oktober 2007 (Stand am 01. Januar 2018) (SR $312.0)$.

${ }^{38} \mathrm{Ch} \_02,00: 04: 34$.

${ }^{39}$ Germ_01, 00:44:57; Germ_05, 00:10:09.

${ }^{40}$ Germ_04, 00:18:14; Germ_05, 00:18:56; Sing_01, 00:22:48; Sing_03, 00:18:31.

${ }^{41}$ Germ_04, 00:09:13; Sing_02, 00:58:44.
} 
illegally obtained evidence ${ }^{42}$ Does the deliberate provocation of an offence by state officials result in the reduction of sentence, the exclusion of thereby collected evidence, or in a procedural impediment? The jurisdiction of the European Court of Human Rights has found that all evidence must be excluded and that measures short of excluding are insufficient to secure a fair trial (in this case, in Germany). ${ }^{43}$ Further problems concern new technical developments that require new techniques to investigate them as well as new possibilities to gain evidence, for example, in the area of telecommunications surveillance including text messages and the analysis of radio cells. ${ }^{44}$ However, in some cases it depends on the legal culture, whether the tactic of questioning can still be certified as legal. In Germany, for example, a tactic that is sometimes used to get a suspect to talk is to say that their accomplice has made a statement. ${ }^{45}$ It must be concluded that such legal grey-zones are open to misuse. Before evidence can be excluded, a claim of such has to be made by the suspect. One expert made reference to his experience with the assertion of claims after evidence was obtained illegally. The injured party, who is the accused, could be too afraid to press charges against police officers, particularly if they are foreigners who are not familiar with the legal system. ${ }^{46}$

\subsubsection{Limitations of Safeguarding a Fair Trial}

Next to the abovementioned difficulties of the legal applicability, exclusionary rules are faced with several limitations.

\subsubsection{Subjective Assessments and Balancing Process}

Some limitations, particularly an assumed dependence on subjective assessment by courts, judges, prosecutors or police officers, are inherent in the legal system. They particularly appear in cases of balancing competing interests: the guarantee of valid information on one hand and inalienable rights of the suspect on the other hand. ${ }^{47}$ Despite the legal need for an extensive balancing of arguments, information and evidence, experts from all countries pointed out the imponderability of a balancing procedure. ${ }^{48}$ During the criminal proceeding, the careful balancing of exclusionary

\footnotetext{
${ }^{42}$ Sing_02, 00:58:44.

${ }^{43}$ European Court of Human Rights (ECtHR), Frucht v. Germany, case no. 54648/09, Judgement (5.Chamber) of 23 October 2014 at $\S 68$.

${ }^{44}$ Germ_04, 00:30:11.

${ }^{45}$ Germ_04, 00:25:46.

${ }^{46}$ Sing_03, 00:43:04, 00:43:09.

${ }^{47}$ Germ_03, 01:16:01.

${ }^{48}$ Germ_02, 01:08:54; Germ_03, 01:35:15; Sing_01, 00:22:48; Taiw_03, 00:52:20.
} 
rules includes risks of wrong decisions being made. ${ }^{49}$ For example: where does the effect of coercion end? Where is the line between legal and illegal influence through tactical interrogation by police officers or prosecutors ${ }^{50}$ Which information collected by police officers is comprised in a case file? Generally, police officers preselect the information included in the file. ${ }^{51}$ It is not predictable, how evidence is evaluated by the judge or prosecutor ${ }^{52}$ and to which extent a prosecutor, police officer or judge is influenced by the impression of a suspect, when the credibility of an accused person has to be examined.

\subsubsection{Credibility and Proof of Violations of Rules}

The credibility of a claim pertaining to illegally obtained evidence is another imponderability. It is questionable, how a suspect can prove threats, inducements, promises, pressure or use of force to gain a statement, confession or evidence. If the suspect claimed to be beaten by police or exposed to undue coercion, he has to state the circumstances and sometimes prove them. ${ }^{53}$ During the investigation process, prosecutors or (pretrial) judges evaluate the claim and possible evidence. How can the deprivation of sleep or food and drinks be proved? In Taiwan (ROC) the person concerned has, in some cases, to sign a form which voluntarily allows for the police to conduct a search. ${ }^{54}$ How can the affected person prove that he/she felt under pressure to sign? Such cases of controversial provability and credibility can also include serious accusations against police officers, for example the suspect made a confession immediately after an unexpected and undue arrest by special police forces. ${ }^{55}$ Did the suspect confess voluntarily or under the maintenance of pressure? How reliable is a confession after an extended time-period of interrogation? In the end, it is a matter of who to believe: the police or the accused. Crucial factors that determine the credibility of claimed illegally obtained evidence are the plausibility of the assertion, inside-knowledge about involved policemen (are they known as quick-tempered or calm characters?), but also possible motives of the suspect to claim, for example the crown witness programme. ${ }^{56}$ However, the uncertainty will clearly remain about the veracity of the confession. ${ }^{57}$

\footnotetext{
${ }^{49}$ Germ_05, 00:20:57.

${ }^{50}$ Germ_04, 00:04:42.

${ }^{51}$ Germ_04, 00:10:50.

${ }^{52}$ Sing_01, 00:22:48.

${ }^{53} \mathrm{Ch} \_02,00: 39: 25$; Germ_05, 00:15:22, 00:15:53.

${ }^{54}$ Taiw_03, 00:46:01.

${ }^{55}$ Germ_05, 00:15:22.

${ }^{56}$ Germ_04, 00:27:02.

${ }^{57}$ Taiw_04, 00:55:46.
} 


\subsubsection{Extend of Protection}

The question of the extent to which a suspect can and should be protected is closely connected to the provability of inducement and/or threat. Situations where a suspect is questioned without being informed of his/her rights could occur, for example, when he/she waits in the police station and smokes with officers or when he/she is driven to be taken into custody in another city. ${ }^{58}$ One expert recounted a case in which a bound suspect (hand and foot cuffs) was not properly fastened in the car so that he lost his balance. ${ }^{59}$ Who is responsible and takes care in such a situation? Could such a situation be misused by officers to maintain inducement? In the mentioned case, the judge responsible for the pretrial detention investigated the assertion, spoke to the involved officers and discussed solutions. ${ }^{60}$ But the judge had to trust the officer and could not control whether something else happened during the ride. Threats or inducements were not claimed, but could be easily expressed or maintained in nearly all situations (for example the abovementioned arrest through special police forces).

\subsubsection{Knowledge of the Excluded Evidence}

Another limitation exists in countries where the same judge decides about the admissibility of the evidence and the case. Even if the illegally obtained evidence is excluded, the court knows about it and could be influenced in decision-making or try to evade the undesired outcome. ${ }^{61}$ Referring to German law ( $\$ 257$ Criminal Procedure Code), the accused and his defense counsel have the opportunity to make a statement after evidence has been taken. If no statement is given, the tainted evidence could be used. If an accused is not represented by a lawyer, he may not know the legal possibilities, which leads to a legal limitation. ${ }^{62}$ A German prosecutor mentioned that it is sometimes difficult to know more information about an accused if that information is not admissible in the criminal proceeding. However, it has to be taken into consideration that the judge, who does not know these information, remains impartial. ${ }^{63}$

\footnotetext{
${ }^{58}$ Germ_04, 00:43:11; Germ_04, 00:44:55.

${ }^{59}$ Germ_02, 00:56:49.

${ }^{60}$ Germ_02, 00:56:49.

${ }^{61}$ Ch_01, Sec.12; Taiw_04, 00:31:49.

${ }^{62}$ Germ_01, 00:07:31.

${ }^{63} \mathrm{Germ} \_04,00: 25: 05$.
} 


\subsubsection{Responsibilities and Control}

Further protection gaps concern the control of police. Contrary to the situation in Germany or Switzerland, in Singapore, police forces are independent from the prosecution service. ${ }^{64}$ Prosecutors cannot instruct police and control their daily work. In Taiwan (ROC), control of the police is often lacking due to a work overload of prosecutors. ${ }^{65}$ Nevertheless, it is questionable whether informal control options, or independent investigations, lead to more control and pressure to obtain evidence legally. A limitation here is the allocation of responsibilities that depends on the personality of the responsible judge or prosecutor. If the judge/prosecutor is responsible, the prosecutor/judge will maybe remain silent if a defendant with a black eye arrives, arguing he/she is not responsible in this part of the process. ${ }^{66}$

The described limitations take place at a human level that can be influenced and standardized, but lawyers, courts and prosecutors should be aware of limitations. Challenges referring to provability and the extent of protection could be solved by legal rules or using new techniques like video or audio taping, physical examinations after arresting someone or control measures. ${ }^{67}$ Others limitations are dependent on balancing and the attitudes of the people deciding.

\subsection{Compliance with Rules to Obtain Evidence}

All legal systems are faced with deviance. Deviations from norms ultimately enhance for social cohesion and justify the legitimacy of the criminal law and state-run institutions like prosecutions service and criminal courts. ${ }^{68}$ As a matter of fact, use of illegally obtained evidence is possible in each and every legal system. Violations of rules to obtain evidence are a highly sensitive area, as the state, represented by police officers and the prosecution service, has an overpowering role. The following chapter deals with awareness for exclusionary rules, possibilities of contributing to norm compliance and the discussion of measures suitable to safeguard proper evidence procedures.

\footnotetext{
${ }^{64}$ Sing_02, 00:16:11.

${ }^{65}$ Taiw_03, 00:22:55.

${ }^{66} \mathrm{Ch} \_02,00: 11: 05$; Germ_01, 00:14:25.

${ }^{67}$ See below: Section 3.4.1.

${ }^{68}$ Lamnek, 2007 at 44 et seq.
} 


\subsubsection{Motivation of Norm Compliance and Awareness of Illegally Obtained Evidence}

Based on their long-time professional experience with criminal investigations and criminal proceedings, the questioned experts agreed, as previously mentioned, that torture and undue coercion are an exceptional phenomenon. Although the exclusion of evidence is not an important issue in the experts' daily work, and exclusion is regularly focused on particularly serious crimes, investigation officers obtain evidence daily and this should be gathered legally. The system relies on legally obtained evidence. Which factors motivate officers to gain evidence legally, even if it is maybe easier to gain it illegally? Are they deterred by deterrence strategies or do normative considerations play a role? Understanding people's motives is an important step in identifying measures of prevention. What motivates police officers and prosecutors to comply with legal regulations: (1) fear of criminal liability, (2) fear of consequences under employment law, (3) fear of being detected, (4) acceptance of the necessity of exclusionary rules and (5) fear of wasting time if evidence has to be excluded due to illegal methods? While the first three points are based on the idea of rational choice, the fourth and fifth issues are focused on normative considerations. Experts pointed out that police officers are generally motivated to do excellent work, to avoid mistakes and to prepare, as far as possible, police operations to be conducted legally. ${ }^{69}$ This motivation includes the fear to waste time, if an evidence has to be excluded after spending weeks or months for investigation. ${ }^{70}$ One expert is convinced that the rationale behind prohibited measures of interrogation is convincing in a constitutional state and is usually internalized by every police officer. ${ }^{71}$ It is assumed that legal consequences have a preventive effect on investigation officers, if they witness that their colleague is punished, suspended and maybe loses their future pension. ${ }^{72}$

Norm compliance and prevention also require awareness. If society tolerates deviant behaviour, deviant behaviour can be normalised. ${ }^{73}$ To analyze their awareness of illegal measures to obtain evidence, the example of a suspect with a black eye was raised with the experts. The presumed case included a suspect with a black eye brought by police to court. The suspect later withdrew his confession due to undue coercion. Asked what they would think in such a situation, some experts were surprised and convinced that such things won't happen. One expert assumed that the accused was involved in a fight in jail. ${ }^{74}$ Depending on their personality and position, a judge or prosecutor feels or does not feel responsible to investigate the

\footnotetext{
${ }^{69}$ Germ_01, 00:20:07; Germ_05, 00:12:01.

${ }^{70} \mathrm{Ch} \_02,00: 52: 51$, Germ_03, 01:25:37.

${ }^{71}$ Germ_01, 00:18:57.

${ }^{72}$ Germ_03, 01:27:19; Sing_01, 00:26:13.

${ }^{73}$ Wagner, 2010 at 88 .

${ }^{74}$ Germ_01, 00:15:13.
} 
case and to ask the accused person what has happened. ${ }^{75}$ One expert pointed out the specific duty of care for persons concerned by enforcement measures like pretrial detention. $^{76}$ If it is necessary, an investigation of the case has to be started. ${ }^{77}$

\subsubsection{Protective Measure to Safeguard the Legal Obtainment of Evidence}

Finally, the experts were asked about consequences after evidence was illegally obtained and possible incentives to stop public officials from illegally obtaining evidence. Are exclusionary rules sufficient safeguards or are further safeguards during criminal proceedings necessary?

\subsubsection{Legal Consequences for Police Officers}

The experts agreed that police misconduct is taken seriously, in order to safeguard a fair trial. It is, depending on the credibility of the accusation, regularly investigated if it is mentioned by the affected person. ${ }^{78}$ If misconduct by civil servants can be proved, there will be consequences under employment law, civil liability, disciplinary action and ultimately criminal liability. ${ }^{79}$ As described above, experts assumed that legal consequences have a preventive effect on investigation officers. It was noted that the necessity of serious personal legal consequences should be dependent on the seriousness of the infringement. ${ }^{80}$ One expert added that the mere violation of procedural rules should not be prosecutable, if no crime is committed. ${ }^{81}$

\subsubsection{Legal Consequences for the Affected Person}

In addition to the exclusion of illegally obtained evidence, the affected person can claim compensation for personal suffering as well as damages. ${ }^{82}$ In general, people must be aware of their rights. ${ }^{83}$ A reduction of the sentence was evaluated as

\footnotetext{
${ }^{75}$ Ch_02, 00:10:22, 00:11:05; Germ_01, 00:15:30; Germ_02, 00:52:44; Germ_04, 00:11:48; Taiw_01, 00:54:11.

${ }^{76}$ Germ_02, 00:52:44.

${ }^{77}$ Ch_02, 00:10:52; Germ_02, 00:51:43.

${ }^{78}$ Germ_03, 00:16:49; Sing_01, 00:34:08.

${ }^{79}$ Germ_02, 00:52:44; Germ_03, 00:21:54; Ch_02, 00:59:48, 00:59:51; Sing_01, 00:14:54, 00:45:34; Sing_03, 00:45:02; Taiw_03, 00:55:27, 00:56:43; Taiw_02, 00:23:33.

${ }^{80}$ Sing_02, 01:08:26.

${ }^{81}$ Germ_01, 00:28:41.

${ }^{82}$ Ch_02, 01:00:53; Germ_04, 00:59:50; Sing_03, 00:45:02; Taiw_01, 00:58:32.

${ }^{83}$ Sing_02, 01:10:43.
} 
controversial. Mainly the experts agreed not to reduce the sentence, but it was remarked that in Germany the illegal obtainment of evidence could be taken into account. ${ }^{84}$ As discussed, controversial evidence is of little value, and judges tend to exclude this evidence if there are any doubts that a confession could be unlawful. Usually, the judgement is based on several pieces of evidence. ${ }^{85}$

\subsubsection{Control Measures: Physical Examinations, Recording of Interrogations, Participation of Lawyers}

Control measures have a twofold purpose: on the one hand they increase detection of undue coercion, on the other hand they enable illegal behavior to be proved. The audio and or video recording of police interrogations and hearings, implemented in different degrees in Taiwan (ROC) and Singapore, ${ }^{86}$ is used to provide proof of potential misconduct to prevent investigation officers from using coercion. ${ }^{87}$ Experts evaluate the recording of hearings as positive. Nevertheless, loopholes are possible, for example, before the recording starts or on the way to the hearing. ${ }^{88}$ In the abovementioned example of an accused with a black eye, Taiwanese experts mentioned their mechanism to mitigate such possible misconducts. Accused are physically examined at their arrest and have to be brought before an investigation magistrate within $24 \mathrm{~h}$ of being arrested. If the person has injuries that are not documented at the time of arrest, the injuries must have happened while he/she was in pretrial custody. ${ }^{89}$ One expert recommended the participation of a lawyer in hearings to safeguard the accused's rights. ${ }^{90}$

\subsubsection{Practical Measures and Incentives}

In Germany, the responsibilities of police officers working in larger police departments are usually divided. While (special) forces are responsible for arrest, officers from criminal investigation departments are responsible for conducting interrogations. The division of responsibilities is described as positive to enhance an

\footnotetext{
${ }^{84} \mathrm{Ch} \_02,01: 02: 53$; Germ_04, 01:04:18; Sing_01, 00:47:53; Sing_02, 01:15:55; Sing_03, 00:47:01; Taiw_01, 01:04:13.

${ }^{85}$ Germ_04, 00:18:14, 00:47:14; Germ_05, 00:13:11.

${ }^{86}$ In Singapore, the audio- and video-recording was implemented as a pilot project.

${ }^{87}$ Taiw_02, 00:36:13; Taiw_01, 00:36:09, Taiw_04, 00:50:05, Sing_02, 00:48:31, Sing_03, 00:11:48.

${ }^{88}$ Sing_01, 00:20:03, Sing_02, 00:48:31, 00:49:44, Sing_03, 00:11:48.

${ }^{89}$ Taiw_01, 00:40:41.

${ }^{90} \mathrm{Ch} \_01$, Sec. 16.
} 
internal control system and social control. ${ }^{91}$ As the legal obtainment of evidence and a fair trial should be the rule, incentives for lawful conduct are not necessary. ${ }^{92}$

\subsubsection{Training of Police Officers and Communication}

The experts agreed that police officers are well-educated and endeavor to comply with the law, but legal regulations are sometimes confusing and their application in stressful situations can be difficult. ${ }^{93}$ Problems particularly occur if small local police stations are responsible for everything. ${ }^{94}$ Some police headquarters offer internal trainings for difficult issues arising in criminal proceedings. ${ }^{95}$ Legal training of police officers and communication with police officers were seen as important measures, not only to educate police, raise awareness for exclusionary rules and provide a fair trial, but also to reduce prejudices against judges and prosecutors, to develop an understanding for their (ex post) decisions, to demonstrate social control and to reduce the officer's potential frustration by explaining the reasons for a decision. ${ }^{96}$ Communication and education cannot replace exclusionary rules, but enhanced attitudes could influence the acceptance of norms, procedural justice and norm compliance.

\section{Conclusion}

Do theory and practice form a well-balance whole and are practitioners concerned about possible limitations and difficulties related to exclusionary rules? The interviewed experts agreed that the use of illegally obtained evidence before courts is rare and that torture and other undue coercion are an exceptional phenomenon. In particular, the German experts pointed out the police officers have usually internalized the principles of the rule of law. Despite all safeguards, every system is nevertheless aware that a suspect's rights may be violated, for example through undue coercion on the way from a police station to court or jail. When accusations of illegally obtained evidence are raised, judges have to balance the competing interests and arguments of both sides. Compliance with the law depends on control measures and the threat of legal consequences, but also on attitudes and awareness of investigating officers. Therefore, proper training and the use of internal incentives amongst police and investigating officers are considered more useful than

\footnotetext{
${ }^{91}$ Germ_04, 00:14:02.

${ }^{92}$ Germ_04, 00:58:47.

${ }^{93}$ Germ_02, 00:50:23, Germ_04, 00:30:11.

${ }^{94}$ Germ_04, 00:27:59.

${ }^{95}$ Germ_01, 00:32:42.

${ }^{96}$ Germ_03, 01:24:15; Germ_04, 01:09:37.
} 
more detailed and complex exclusionary rules. On the other hand, measures like audio and video recording as well as physical examinations and the participation of lawyers can help control officers and enable accused persons to prove claimed illegal behavior. In conclusion, it can be said that despite the existence of some loopholes, exclusionary rules-when accompanied by protective, deterrent and educational measures - do provide the basis for a fair trial.

\section{References}

\section{Books}

Bogner, Alexander/Littig, Beate/Menz, Wolfgang, Interviews mit Experten, Wiesbaden 2014. [Bogner/Littig/Menz, 2014]

Gläser, Jochen/Laudel, Grit, Experteninterviews und qualitative Inhaltsanalyse, Wiesbaden 2010. [Gläser/Laudel, 2010]

Jugl, Benedikt, Fair Trial als Grundlage der Beweiserhebung und Beweisverwertung im Strafverfahren, Baden-Baden 2017. [Jugl, 2017]

Lamnek, Siegfried, Theorien abweichenden Verhaltens, München 2007. [Lamnek, 2007]

Lind, Edgar/Tyler, Tom R., The Social Psychology of Procedural Justice, New York 1988. [Lind/ Tyler, 1988]

Mayring, Philipp, Einführung in die qualitative Sozialforschung, Weinheim, Basel 2002. [Mayring, 2002]

Mayring, Philipp, Qualitative Inhaltsanalyse, Weinheim, Basel 2015. [Mayring, 2015]

Tyler, Tom R., Why people obey the law?, New Haven 1990. [Tyler, 1990]

\section{Journal articles}

Becker, Gary S., 'Crime and punishment: an economic approach', (1968) 78 Journal of Political Economy, 169-217. [Becker, 1968]

Jackson, Jonathan/Bradford, Ben/Hough, Mike/Myhil, Andy/Quinton, Paul/Tyler, Tom. R., 'Why people obey the law? Legitimacy and the Influence of Legal Institutions', (2012) 52 British Journal of Criminology, 1051-1071. [Jackson et al., 2012]

Tyler, Tom R., 'Procedural Justice, Legitimacy, and the Effective Rule of Law', (2003) 30 Crime and Justice, 283-357. [Tyler, 2003]

\section{Contributions to Edited Volumes and Annotated Law}

Bottoms, Anthony E., 'Compliance and community penalties', in: A. Bottoms (ed.), Community penalties change and challenges, Cullompton 2001, 87-116. [Bottoms, 2001]

Clarke, Ronald V., 'Introduction', in: R. Clarke (ed.), Situational Crime Prevention. Successful Case Studies, New York 1997, 1-44. [Clarke, 1997]

Wagner, Matthias, 'Die moralische Ökonomie des Schmuggels', in: M. Wagner/W. Łukowski (eds.), Alltag im Grenzland, Wiesbaden 2010, 73-89. [Wagner, 2010] 


\section{Interviews}

Germany: interview conducted in German.

Germ_01: Judge, District Court. Conducted by Gless, Sabine in November 2015.

Germ_02: Judge, Federal Court. Conducted by Gless, Sabine in November 2015.

Germ_03: Judge, Federal Court. Conducted by Gless, Sabine in November 2015.

Germ_04: Prosecutor. Conducted by Knickmeier, Susanne/ Richter, Thomas in February 2016.

Germ_05: Judge, District Court. Conducted by Gless, Sabine in November 2015.

Singapore: interview conducted in English.

Sing_01: Lawyer. Conducted by Gless, Sabine in February 2016.

Sing_02: Lawyer. Conducted by Gless, Sabine in February 2016.

Sing_03: Lawyer. Conducted by Gless, Sabine in February 2016.

Switzerland: interview conducted in German.

Ch_01: Lawyer. Conducted by Gless, Sabine in February 2016.

Ch_02: Prosecutor. Conducted by Macula, Laura in April 2016.

Taiwan (ROC): interview conducted in Chinese, translated to German.

Taiw_01: Judge. Conducted by Richter, Thomas in March 2016.

Taiwan (ROC): interview conducted in German.

Taiw_03: Lawyer, former prosecutor. Conducted by Richter, Thomas in March 2016.

Taiwan (ROC): interview conducted in English.

Taiw_02: Prosecutor. Conducted by Richter, Thomas in March 2016.

Taiwan (ROC): interview conducted in Chinese, translated to English.

Taiw_04: Lawyer. Conducted by Richter, Thomas in March 2016.

Susanne Knickmeier is a German lawyer who also holds a master's degree in criminology. She is a researcher at the Max Planck Institute for Foreign and International Criminal Law in Freiburg, Germany. Her research focuses on organized crime, economic and industrial espionage, as well as trust in the justice system and European criminal and security policy, with a particular focus on migration, human rights, and border security.

Open Access This chapter is licensed under the terms of the Creative Commons Attribution 4.0 International License (http://creativecommons.org/licenses/by/4.0/), which permits use, sharing, adaptation, distribution and reproduction in any medium or format, as long as you give appropriate credit to the original author(s) and the source, provide a link to the Creative Commons license and indicate if changes were made.

The images or other third party material in this chapter are included in the chapter's Creative Commons license, unless indicated otherwise in a credit line to the material. If material is not included in the chapter's Creative Commons license and your intended use is not permitted by statutory regulation or exceeds the permitted use, you will need to obtain permission directly from the copyright holder. 